\title{
Depression in diabetic patients attending University of Gondar Hospital Diabetic Clinic, Northwest Ethiopia
}

This article was published in the following Dove Press journal: Diabetes, Metabolic Syndrome and Obesity:Targets and Therapy II May 2016

Number of times this article has been viewed

\author{
Anteneh Messele Birhanu' \\ Fekadu Mazengia Alemu \\ Tesfaye Demeke Ashenafie ${ }^{3}$ \\ Shitaye Alemu Balcha ${ }^{4}$ \\ Berihun Assefa Dachew ${ }^{5}$ \\ 'School of Medicine, College of \\ Medicine and Health Sciences, Wollo \\ University, Dessie, ${ }^{2}$ Department \\ of Midwifery, ${ }^{3}$ Department of \\ Nursing, ${ }^{4}$ Department of Internal \\ Medicine, College of Medicine and \\ Health Sciences, ${ }^{5}$ Department of \\ Epidemiology and Biostatistics, \\ Institute of Public Health, University \\ of Gondar, Gondar, Ethiopia
}

Background: Diabetes mellitus, frequently associated with comorbid depression, contributes to the double burden of individual patients and community. Depression remains undiagnosed in as many as $50 \%-75 \%$ of diabetes cases. This study aimed to determine the prevalence and associated factors of depression among diabetic patients attending the University of Gondar Hospital Diabetic Clinic, Northwest Ethiopia.

Methods: An institution-based cross-sectional study was conducted from March to May 2014 among 422 sampled diabetic patients attending the University of Gondar Hospital Diabetic Clinic. The participants were selected using systematic random sampling. Data were collected by face-to-face interview using a standardized and pretested questionnaire linked with patient record review. Depression was assessed using the Patient Health Questionnaire-9. Data were entered to EPI INFO version 7 and analyzed by SPSS version 20 software. Binary logistic regression analysis was performed to identify factors associated with depression.

Results: A total of 415 diabetic patients participated in the study with a response rate of $98.3 \%$. The prevalence of depression among diabetic patients was found to be $15.4 \%$ (95\% confidence interval (CI): 11.7-19.2). Only religion (adjusted odds ratio [AOR] $=2.65$ and 95\% CI: $1.1-6.0$ ) and duration of diabetes ( $\mathrm{AOR}=0.27$ and $95 \% \mathrm{CI}$ : 0.07-0.92) were the factors associated with depression among diabetic patients.

Conclusion: The prevalence of depression was low as compared to other similar studies elsewhere. Disease (diabetes) duration of 10 years and above and being a Muslim religion follower (as compared to Christian) were the factors significantly associated with depression. Early screening of depression and treating depression as a routine component of diabetes care are recommended. Further research with a large sample size, wider geographical coverage, and segregation of type of diabetes mellitus is recommended.

Keywords: depression, diabetes, University of Gondar Hospital

\section{Introduction}

Diabetes mellitus (DM) is increasingly recognized as a serious global health problem. Based on a World Health Organization report, the prevalence of diabetes in all age groups worldwide was estimated to be $2.8 \%$ in 2000 and will be $4.4 \%$ in $2030 .{ }^{1}$

Currently, diabetes affects low-income and developing countries, which have the

Correspondence: Berihun Assefa Dachew Department of Epidemiology and Biostatistics, Institute of Public Health, University of Gondar, PO Box 196, Gondar, Ethiopia

$\mathrm{Tel}+25$ I $91 \quad 1542348$

Email berihunassefa2।@gmail.com fastest growing numbers of newly diagnosed patients. ${ }^{1}$ Ethiopia is one of the top five countries with the highest number of people affected by DM in Sub-Saharan African courtiers. ${ }^{2}$ The prevalence of DM in Ethiopia was 2.5\% in the year 2000 and was estimated to rise to $3.5 \%$ by $2030 .^{3}$ submit your manuscript | www.dovepress.com

Dovepress

http://dx.doi.org// 0.2147/DMSO.S97623 
Depression is the third leading cause of burden of diseases worldwide, representing $4.3 \%$ of the total disability-adjusted life years. It is also predicted to become the second leading cause of the global disease burden by the year $2020 .{ }^{4}$ In Ethiopia, depression contributes to $\sim 6.5 \%$ of the burden of diseases. This is the highest share of burden compared to other forms of mental disorders. ${ }^{5,6}$

There are evidences that suggest the bidirectional relationship between depression and diabetes, ${ }^{7-9}$ with depression developing earlier in life leading to an increased risk of diabetes ${ }^{7,8}$ and diabetes increasing the subsequent risk of depression. ${ }^{7}$ In addition to being a risk factor for diabetes,${ }^{10}$ depression with diabetes increases the risk of developing diabetes-related complications (diabetic retinopathy, nephropathy, neuropathy, macrovascular complications, and sexual dysfunction). ${ }^{11}$

A 5-year prospective cohort study also revealed that major depression among type II diabetes patients is associated with an increased risk of clinically significant microvascular (blindness, end-stage renal disease, amputation, and renal failure death) and macrovascular (myocardial infarction, stroke, cardiovascular procedures such as angioplasty and stent placement, and death) complications. ${ }^{12}$ In addition, it is evidenced in many studies that comorbid depression is associated with poor adherence to self-care regimens (adherence to diet, exercise, disease control medication, and cessation of smoking recommendations), ${ }^{13}$ higher medical costs, ${ }^{14}$ and greater mortality among patients with diabetes. On the other hand, poor adherence to self-care regimens is associated with depression, which may increase the risk of diabetes complications and mortality. ${ }^{11-15}$ Diabetes complications may, in turn, precipitate a depressive episode. ${ }^{15}$

Depression remains undiagnosed in $50 \%-75 \%$ of diabetes cases $;{ }^{16}$ it may be untreated or undertreated in individuals with type II diabetes, and untreated depression may further exacerbate the progression of diabetes. ${ }^{17,18}$ The prevalence of depression varies from $9 \%$ to $16 \%$ among hospitalized diabetes patients. ${ }^{19}$ The finding in one US study revealed that nearly $18 \%$ of diabetes patients had major depression, ${ }^{20}$ while another study among US Hispanics showed that $30.2 \%$ of patients met criteria for major depressive disorder. ${ }^{21}$ Another study revealed that $11 \%-31 \%$ of patients with diabetes have depression or clinically significant depressive symptoms. ${ }^{16}$

A meta-analysis of 42 studies found that $~ 20 \%-40 \%$ of individuals with type II diabetes have comorbid depression. ${ }^{22}$ A systematic review and meta-analysis study showed that the prevalence of depression was higher in females with diabetes (23.8\%) compared with males $(12.8 \%) .{ }^{23}$ The prevalence of major depression among type II diabetes patients is $20 \%,{ }^{23}$ and it was found to be $40.3 \%$ in one Malaysian study. ${ }^{24}$ Other studies showed that the prevalence of depression among patients with DM was $43.5 \%$ in Pakistan, ${ }^{25} 40 \%$ in Palestine, ${ }^{26}$ and $7.8 \%$ in Nigeria. ${ }^{27}$ Studies in Ethiopia revealed that the magnitude of depression among diabetic patients ranged from $13 \%$ to $61 \% .^{28,29}$

Poor adherence to self-care regimens (nonadherence to diet, exercise, smoking, and taking prescribed medication), ${ }^{13,15}$ increased body mass index (BMI), ${ }^{12,30}$ pain, limited mobility, and poor glycemic control ${ }^{20}$ are associated with depression among patients with DM. Research has been conducted to determine the prevalence and predictors of depression among diabetes patients in the developed world. However, only a few studies have been conducted in Ethiopia, and no studies have been conducted in the study area to determine the prevalence and predictors of depression among diabetes patients.

Therefore, this study aimed to determine the prevalence of depression and associated factors among diabetic patients attending the University of Gondar Hospital (UoGH) Diabetic Clinic, Northwest Ethiopia. The result of the study will help to design more effective programs in the management of comorbid diabetes and depression among diabetes patients. It will also be helpful to assist in developing practice protocols and standardization of practice guidelines. In addition, the finding of the study will be used as a baseline for other researchers who want to conduct a large-scale study in the country.

\section{Materials and methods \\ Study setting}

An institution-based cross-sectional study was conducted from March 10, 2014 to May 30, 2014. The study was conducted at the UoGH Diabetic Clinic. The university is located at the heart of the historic Gondar city which is located $720 \mathrm{~km}$ northwest of Addis Ababa. It has a population of $\sim 5$ million. ${ }^{31}$ More than 3,000 diabetic patients were registered in the UoGH Diabetic Clinic, but those patients with active DM follow-up were $\sim 2,000$, while the remaining patients were followed in the eight rural health centers included in the project.

\section{Study participants}

The study population included diabetic patients who were under medical supervision/followed up on the UoGH Diabetic Clinic, who had a documented diagnosis of diabetes type I or II, and whose age was 18 years or above. Those who 
were seriously ill at the time of data collection were excluded from the study.

\section{Study variables}

The dependent variable was depression. The independent variables included in the study were sociodemographic, clinical, and self-care characteristics; use of psychotropic drug; poor glycemic control; duration of diabetes; and diabetic complications.

\section{Operational definition}

Depression: A patient with a score of 5 and above in the Patient Health Questionnaire (PHQ) was considered having depression. PHQ-9 depression subscales were classified as no depression if the PHQ-9 score was 0-4, mild depression if the PHQ-9 score was 5-9, moderate depression if the PHQ-9 score was 10-14, moderately severe depression if the PHQ-9 score was 15-19, and severe depression if the PHQ-9 score was 20-27.

Good glycemic control: a fasting blood glucose level $\leq 130 \mathrm{mg} / \mathrm{dL}$ was considered good glycemic control.

Poor glycemic control: a fasting blood glucose level $>130 \mathrm{mg} / \mathrm{dL}$ was considered poor glycemic control.

Regular physical activity: regular physical activity was considered if a person exercised for at least 30 minutes or walked for 3 or more days per week.

Current smoker: smoking in the past 30 days before the data collection was considered current smoker.

\section{Sample size determination}

The sample size was determined using Stat Calc (EPI INFO 7.1) program to estimate a single population proportion based on the following assumptions: $95 \%$ level of confidence, $5 \%$ margin of error, and an estimated prevalence of depression of $50 \%$ among diabetic patients. With these assumptions, the resulting sample size became 384 . Therefore, the final minimum sample size (n) became 422 considering 10\% non-response rate.

\section{Sampling procedure}

The systematic random sampling technique was used to select the study participants. The pattern of patient flow rate in the diabetic clinic was considered. As a result, the average patient flow rate was calculated to be 97 . The average flow rate was multiplied by the data collection period. The sampling interval was five; hence, the patients included in the sample were selected every fifth interval. The first patient was selected randomly from the first five by a lottery method, and the next patient was interviewed every fifth interval.

\section{Data collection instrument}

Standardized, valid, and reliable PHQ-9 was used to assess depression. The tool was validated in East Africa including Ethiopia. ${ }^{32}$ PHQ-9 is a nine-item self-report instrument (scoring ranges from 0 to 27) used to assess depression. This questionnaire can be used to diagnose major depression, according to the Diagnostic and Statistical Manual of Mental Disorders-IV (DSM-IV) criteria and a continuous severity scale. The response item choices of the PHQ-9 range from 0- (not at all), 1- (several days), 2- (more than half the days), to 3- (nearly every day). In addition to depression, the questionnaire had questions concerning sociodemographic, clinical, and self-care characteristics. The English version of the instrument was translated to the local language (Amharic) and translated back to English by language experts. The original and translated questionnaires were compared and the discrepancies were reviewed and resolved accordingly.

\section{Anthropometric measurements}

A studio meter with a movable headboard capable of measuring to the nearest $0.1 \mathrm{~cm}$ was used to measure the height of the subjects. Each subject was requested to stand on the surface, with weight distributed evenly on both the feet, heels together against the studio meter, and the head positioned so that the line of vision was perpendicular to the body. The well-calibrated scale was used to weigh the study participants. To avoid the variability among the data collectors, the same measurement was employed for a given anthropometric measurement more than one time. Finally, BMI was calculated as $\mathrm{kg} / \mathrm{m}^{2}$ to determine the nutritional status of body composition.

\section{Data collection methods}

Data were collected through face-to-face interviews and record interviews. Data collection was undertaken by two trained degree holder nurses. A 3-day training was given to the data collectors on how to approach the study participants, how to use the questionnaire and guideline, and the techniques of data collection. The investigators closely followed the data collection process and ensured completeness and consistency of the collected questionnaire daily.

\section{Data quality control methods}

The care of the quality of the data began from careful designing of the questionnaire. To ensure the quality of data and cultural competence of the tool, prior to actual data 
collection, pretests of data collection tools were carried out on 32 diabetes patients attending Felege Hiwot Hospital Diabetic Clinic. After analyzing the pretest results, necessary modifications and corrections were made accordingly before using the tools in the actual survey. Every day the collected questionnaire was checked for clarity, consistency, and completeness by the investigators. Consequently, amendments and corrections were made before the start of the next day's work. Data double entry was done for reliability and correctness with the respective original data. In addition, computer data cleaning was undertaken.

\section{Data processing and analysis}

The questionnaire was coded and entered into EPI INFO version 5.3.1, and then it was exported to SPSS version 20 for analysis. Both descriptive and analytical statistical procedures were utilized. Descriptive statistics for the presentation of demographic data, including the gross amount, percentage, or mean and standard deviation (SD) was used. Binary logistic regression was used to identify predictors of depression among diabetes patients. Variables with a bivariate $P<0.20$ were fitted into multivariate models for controlling the possible effect of confounders, and finally the variables that had significant association with depression were identified on the basis of odds ratio (OR), with $95 \%$ confidence interval $(\mathrm{CI})$ and $P<0.05$. The variables were entered into the multivariate model using the backward stepwise (likelihood ratio) method.

\section{Ethics statement}

Ethical approval was secured from the Ethical Review Committee of the College of Medicine and Health Sciences, University of Gondar. Permission to conduct the research was obtained from the Hospital Chief Executive and the Department of Internal Medicine. Written informed consent was obtained from the participants after clear and detailed explanation of the purpose, risks, and benefits of the research. It was explained to the participants that the selection to the study was random. No criteria were used for the selection of participants, and their involvement in the study was on a voluntary basis; they had the right to participate or not. It was explained that there was no risk or punishment for the patients who did not volunteer to participate in the study. Confidentiality was maintained at all stages of the study; only anonymous data were collected, that is, the name and other identifiers were not requested. Any patient assessed to have depression (with a PHQ-9 score of 5 or greater) was referred to the psychiatric clinic for further assessment and management.

\section{Results Sociodemographic characteristics}

A total of 415 diabetic patients participated in the study with a response rate of $98.3 \%$. The mean age of the participants was 44.2 years, with a SD of 15.8 years. Nearly half (48.7\%) of the respondents were females. A higher percentage (65.8\%) of participants had urban background. Almost all of the study participants were from the Amhara ethnic group (99.3\%) and Orthodox Christians (90.8\%). A majority of the participants $(60.7 \%)$ were married and nearly three-quarters $(77.1 \%)$ had children. One-third $(29.9 \%)$ of the participants were homemakers (Table 1).

\section{$\mathrm{BMI}$ of respondents}

The mean BMI of the study participants was $23.6 \mathrm{~kg} / \mathrm{m}^{2}$ with a SD of +4.7 . Nearly one-third $(27.5 \%)$ of the participants were overweight and $7.2 \%$ were obese (Table 1 ).

\section{Clinical and self-care characteristics}

The proportion of DM happened to be equally distributed between the two major types: type I (49.6\%) and type II (50.4\%). Most study participants had diabetes for $<5$ years (59.5\%), and more than three-fourth (78.1\%) had not undertaken any physical activity. Among those who undertook physical activity, $14.2 \%$ performed regular physical activity (undertook at least 30 minutes of physical exercise or walked for 3 or more days per week). Sixty percentage of participants were taking insulin for diabetes treatment and were in treatment for $<5$ years since diagnosis. Three-quarters $(72 \%)$ of the respondents had poor glycemic control, onethird $(30.4 \%)$ had one or more diabetic complications, and $10 \%$ had other medical comorbidities (Table 2). The most common diabetic complication was hypertension (30.6\%) (Table 3).

\section{Prevalence of depression among diabetic patients}

The prevalence of depression among diabetic patients was found to be $15.4 \%$ (95\% CI: 11.7-19.2). It was slightly higher in females $(16.3 \%)$ than in males $(14.6 \%)$, though the difference was not statistically significant $\left(\chi^{2}=0.25, P=0.68\right)$. A higher proportion of participants had mild depression $(12.3 \%)$ and $3.1 \%$ had moderate depression. There was no diabetic patient who had severe depression in the current study.

\section{Factors associated with depression}

Only religion (adjusted odds ratio $[A O R]=2.65$ and $95 \%$ CI: 1.1-6.0) and duration of diabetes $(\mathrm{AOR}=0.27$ and $95 \%$ 
Table I Sociodemographic characteristics of diabetic patients attending UoGH Diabetic Clinic ( $n=4 \mid 5)$, Gondar, Northwest Ethiopia, November 2014

\begin{tabular}{|c|c|c|}
\hline Variables & & Number (\%) \\
\hline \multirow[t]{5}{*}{ Age (years) } & $18-29$ & 91 (21.9) \\
\hline & $30-39$ & $70(16.9)$ \\
\hline & $40-49$ & $69(16.6)$ \\
\hline & $50-59$ & $132(3 \mid .8)$ \\
\hline & $>60$ & $53(12.8)$ \\
\hline \multirow[t]{2}{*}{ Sex } & Female & $202(48.7)$ \\
\hline & Male & $2 \mid 3(5 \mid .3)$ \\
\hline \multirow[t]{3}{*}{ Religion } & Orthodox Christian & $377(90.8)$ \\
\hline & Muslim & $35(8.5)$ \\
\hline & Protestant & $3(0.7)$ \\
\hline \multirow[t]{2}{*}{ Residence } & Urban & $273(65.8)$ \\
\hline & Rural & $142(34.2)$ \\
\hline \multirow[t]{2}{*}{ Ethnicity } & Amhara & $412(99.3)$ \\
\hline & Oromo & $3(0.7)$ \\
\hline \multirow[t]{3}{*}{ Educational status } & Cannot read and write & $240(57.8)$ \\
\hline & $\begin{array}{l}\text { Completed secondary } \\
\text { education }\end{array}$ & $44(10.6)$ \\
\hline & $\begin{array}{l}\text { University/college degree } \\
\text { and above }\end{array}$ & $24(5.8)$ \\
\hline \multirow[t]{9}{*}{ Occupation } & Housewife & $124(29.9)$ \\
\hline & Government employer & $70(16.9)$ \\
\hline & Merchant & $33(8)$ \\
\hline & Farmer & $117(28.2)$ \\
\hline & Daily laborer & $17(4.1)$ \\
\hline & Pensioner & $15(3.6)$ \\
\hline & Self-employed & $15(3.6)$ \\
\hline & No job & $9(2.1)$ \\
\hline & Students & $5(1.2)$ \\
\hline \multirow[t]{4}{*}{ Marital status } & Widow & 48 (II.5) \\
\hline & Divorcee & $50(12.1)$ \\
\hline & Single & $65(I 5.6)$ \\
\hline & Married & $252(60.7)$ \\
\hline Monthly family income & $<25$ & $148(35.7)$ \\
\hline \multirow[t]{2}{*}{ (in USD) } & $(25-50)$ & $164(39.5)$ \\
\hline & $>50$ & $103(24.8)$ \\
\hline \multirow[t]{2}{*}{ Had children } & Yes & $320(77.1)$ \\
\hline & No & $95(22.9)$ \\
\hline \multirow[t]{3}{*}{ BMI $\left(\mathrm{kg} / \mathrm{m}^{2}\right)$} & $<18.5$ & $30(8)$ \\
\hline & $18.5-25.0$ & $238(57.3)$ \\
\hline & $25-30$ & II 4 (27.5) \\
\hline
\end{tabular}

Abbreviations: UoGH, University of Gondar Hospital; BMI, body mass index.

CI: 0.07-0.92) were the factors associated with depression among diabetic patients. In this study, strong predictors of depression like BMI and diabetes complications were not found to be significant (Table 4).

\section{Discussion}

The prevalence of depression in this study was $15.4 \%$. This was lower than that reported by different studies conducted elsewhere. ${ }^{16,20-24,27}$ In the current study, the prevalence of depression was slightly lower than that reported by one study
Table 2 Clinical and self-care characteristics of diabetic patients attending UoGH Diabetic Clinic $(n=415)$, Gondar, Northwest Ethiopia, November 2014

\begin{tabular}{|c|c|}
\hline Variable & Number (\%) \\
\hline \multicolumn{2}{|l|}{ Type of DM } \\
\hline Type II & $206(49.6)$ \\
\hline Type I & $209(50.4)$ \\
\hline \multicolumn{2}{|c|}{ Duration of diabetes since diagnosed (years) } \\
\hline$<5$ & $247(59.5)$ \\
\hline $5-10$ & $117(28.2)$ \\
\hline$>10$ & $30(12.3)$ \\
\hline \multicolumn{2}{|l|}{ Diabetes treatment intensity } \\
\hline None or diet & $4(1)$ \\
\hline Oral hypoglycemic only & $150(36.1)$ \\
\hline Insulin only & $249(60)$ \\
\hline Insulin and oral hypoglycemic & $12(2.9)$ \\
\hline \multicolumn{2}{|c|}{ Years in treatment since diabetes diagnosis } \\
\hline$<5$ & $250(60.2)$ \\
\hline $5-10$ & $116(28)$ \\
\hline$>10$ & $49(11.8)$ \\
\hline \multicolumn{2}{|l|}{ Glycemic control } \\
\hline Good & $116(28)$ \\
\hline Poor & $299(72)$ \\
\hline \multicolumn{2}{|l|}{ Recent physical exercise } \\
\hline Yes & $91(21.9)$ \\
\hline No & $324(78.1)$ \\
\hline \multicolumn{2}{|l|}{ Regular physical exercise } \\
\hline Yes & $59(14.2)$ \\
\hline No & $356(85.8)$ \\
\hline \multicolumn{2}{|l|}{ Use of psychotropic drugs } \\
\hline Yes & $2(0.5)$ \\
\hline No & $413(99.5)$ \\
\hline \multicolumn{2}{|l|}{ Current smoker } \\
\hline Yes & $\mathrm{I}(0.2)$ \\
\hline No & $414(99.8)$ \\
\hline \multicolumn{2}{|l|}{ Presence of medical comorbidities } \\
\hline Yes & $38(9.2)$ \\
\hline No & $377(90.8)$ \\
\hline \multicolumn{2}{|l|}{ Diabetic complications } \\
\hline Yes & $126(30.4)$ \\
\hline No & $289(69.6)$ \\
\hline
\end{tabular}

Abbreviations: UoGH, University of Gondar Hospital; DM, diabetes mellitus.

in the USA $(18 \%){ }^{20}$ It was also lower than that observed in the studies conducted in Pakistan (43.5\%), ${ }^{25}$ Malaysia (40.3\%), ${ }^{24}$ Nepal (40.3\%), ${ }^{33}$ Palestine (40\% ), ${ }^{26}$ US Hispanics (30.2\%), ${ }^{21}$ and Nigeria $(27.8 \%) .{ }^{27}$ The possible explanation for the difference might be due to the differences in lifestyle, perceived severity of the disease, religion, and social integrity of the patients. Moreover, the current finding is also very much lower than in a study conducted in other parts of Ethiopia (61\%). ${ }^{28}$ The difference might be due to differences in the types of diagnostic tools used (as the previous study used the Hamilton Depression Rating Scale to diagnose depression). However, the finding of the current study is in line with 
Table 3 Diabetic complications of diabetic patients attending UoGH Diabetic Clinic ( $n=4 \mid 5)$, Gondar, Northwest Ethiopia, November 2014

\begin{tabular}{ll}
\hline Variable & Number (\%) \\
\hline Hypertension & $127(30.6)$ \\
Yes & $288(69.4)$ \\
No & \\
Nephropathy & $13(3.5)$ \\
Yes & $402(96.2)$ \\
No & \\
Retinopathy & $23(5.5)$ \\
Yes & $392(94.5)$ \\
No & \\
Neuropathy & $20(4.8)$ \\
Yes & $392(94.5)$ \\
No & \\
Sexual dysfunction & $2(0.5)$ \\
Yes & $413(99.5)$ \\
No & \\
Amputation & $2(0.5)$ \\
Yes & $413(99.5)$ \\
No & \\
Myocardial infarction & $2(0.5)$ \\
Yes & $413(99.5)$ \\
No & \\
Stroke & $1(0.2)$ \\
Yes & $414(99.8)$ \\
No &
\end{tabular}

Abbreviation: UoGH, University of Gondar Hospital.

another study conducted among type II diabetes patients in Addis Ababa, Ethiopia (13\%). ${ }^{29}$

Although the difference was not statistically significant $\left(\chi^{2}=0.25, \mathrm{P}=0.68\right)$, depression was slightly higher in females $(16.3 \%)$ than in males $(14.6 \%)$ in the current study. This finding is supported by other similar studies. ${ }^{22,25,34}$ In this study, no one had met the criteria for major depression. However, a high proportion of participants in other studies met the criteria for major depression. ${ }^{16,20,21,23}$ This might be due to cross-cultural limitations of diagnostic tools and reporting biases.

Among the non-modifiable factors, religion and duration of diabetes predicted depression among diabetes patients in the current study. Although there is no single study that supports this finding, Muslims were 2.7 times (AOR $=2.65$ and 95\% CI: 1.1-6.0) at increased risk of depression than their Christian counterparts. This might be due to sample size difference (Muslim participants were too small [n=35] as compared to Christian participants [ $\mathrm{n}=380]$ ) or social/cultural differences in reporting depression or a real difference. Further research with a large sample size may be needed to rule out this difference.

Participants whose disease (diabetes) duration was $>10$ years were $73 \%(\mathrm{AOR}=0.27$ and $95 \%$ CI: $0.07-0.92)$
Table 4 Bivariate and multivariate logistic regression analysis of factors associated with depression among diabetic patients attending UoGH Diabetic Clinic, Northwest Ethiopia ( $n=4 \mid 5)$

\begin{tabular}{|c|c|c|c|c|}
\hline \multirow[t]{2}{*}{ Variables } & \multicolumn{2}{|c|}{ Depression } & \multirow{2}{*}{$\begin{array}{l}\text { Crude OR } \\
(95 \% \mathrm{Cl})\end{array}$} & \multirow{2}{*}{$\begin{array}{l}\text { Adjusted OR } \\
(95 \% \mathrm{CI})\end{array}$} \\
\hline & Yes & $\overline{\text { No }}$ & & \\
\hline \multicolumn{5}{|l|}{ Age (years) } \\
\hline $18-29$ & 16 & 75 & $\mathrm{I} .04(0.42-2.55)$ & I.9I (0.50-7.24) \\
\hline $30-39$ & 8 & 62 & $0.63(0.22-1.76)$ & $0.85(0.22-3.17)$ \\
\hline $40-49$ & 11 & 58 & $0.92(0.35-2.43)$ & I.36 (0.4I-4.47) \\
\hline $50-59$ & 20 & 112 & $0.87(0.36-2.06)$ & $0.84(0.3 \mathrm{I}-2.28)$ \\
\hline$>60$ & 9 & 44 & 1.00 & 1.00 \\
\hline \multicolumn{5}{|l|}{ Sex } \\
\hline Female & 33 & 169 & $1.15(0.67-1.95)$ & $0.77(0.33-1.79)$ \\
\hline Male & 31 & 182 & 1.00 & 1.00 \\
\hline \multicolumn{5}{|l|}{ Religion } \\
\hline Christian & 54 & 326 & 1.00 & 1.00 \\
\hline Muslim & 10 & 25 & $2.4(I . I-5.3)$ & $2.65(1.1-6.0)^{*}$ \\
\hline \multicolumn{5}{|l|}{ Residence } \\
\hline Urban & 42 & 231 & $0.99(0.56-1.17)$ & $0.89(0.3 \mid-2.58)$ \\
\hline Rural & 22 & 120 & 1.00 & 1.00 \\
\hline \multicolumn{5}{|l|}{ Marital status } \\
\hline Not married & 28 & 135 & $1.24(0.72-2.13)$ & I.II (0.52-2.36) \\
\hline Married & 36 & 216 & 1.00 & 1.00 \\
\hline \multicolumn{5}{|l|}{ Had children } \\
\hline Yes & 51 & 269 & 1.00 & 1.00 \\
\hline No & 13 & 82 & $0.83(0.43-1.61)$ & $0.88(0.4 \mid-1.88)$ \\
\hline \multicolumn{5}{|l|}{ BMI $\left(\mathrm{kg} / \mathrm{m}^{2}\right)$} \\
\hline$<18.5$ & 10 & 23 & 1.00 & 1.00 \\
\hline $18.5-25.0$ & 33 & 205 & $0.37(0.16-0.84)$ & $0.39(0.16-0.93)$ \\
\hline $25-30$ & 16 & 99 & $0.37(0.15-0.93)$ & $0.33(0.12-0.89)$ \\
\hline$>30$ & 5 & 25 & $0.46(0.13-1.54)$ & $0.35(0.09-1.30)$ \\
\hline \multicolumn{5}{|l|}{ Type of DM } \\
\hline Type I & 30 & 176 & 1.00 & 1.00 \\
\hline Type II & 34 & 175 & $1.14(0.66-1.94)$ & $\mathrm{I} .23(0.58-2.6 \mathrm{I})$ \\
\hline \multicolumn{5}{|c|}{ Duration of diabetes (years) } \\
\hline$<5$ & 44 & 203 & 1.00 & 1.00 \\
\hline $5-10$ & 17 & 100 & $0.78(0.42-1.49)$ & $0.77(0.4 \mathrm{I}-\mathrm{I} .43)$ \\
\hline$>10$ & 3 & 48 & $0.28(0.08-0.96)$ & $0.27(0.07-0.92)^{*}$ \\
\hline \multicolumn{5}{|c|}{ Glycemic control } \\
\hline Good & 18 & 98 & 1.00 & 1.00 \\
\hline Poor & 46 & 253 & $0.99(0.54-1.79)$ & $0.90(0.47-1.7 \mid)$ \\
\hline \multicolumn{5}{|c|}{ Regular physical exercise } \\
\hline Yes & 7 & 52 & $\mathrm{I} .4 \mathrm{I}(0.6 \mathrm{I}-3.27)$ & $0.75(0.29-1.94)$ \\
\hline No & 57 & 299 & 1.00 & 1.00 \\
\hline \multicolumn{5}{|c|}{ Medical comorbidities } \\
\hline Yes & 5 & 33 & $0.81(0.30-2.17)$ & $0.84(0.29-2.39)$ \\
\hline No & 59 & 318 & 1.00 & 1.00 \\
\hline \multicolumn{5}{|c|}{ Diabetes complication(s) } \\
\hline Yes & 22 & 104 & $1.24(0.70-2.18)$ & $\mathrm{I} .65(0.88-3.08)$ \\
\hline No & 42 & 247 & 1.00 & 1.00 \\
\hline
\end{tabular}

Note: *Statiscally significant at $P<0.05$.

Abbreviations: UoGH, University of Gondar Hospital; OR, odds ratio; $\mathrm{Cl}$, confidence interval; $\mathrm{BMI}$, body mass index; DM, diabetes mellitus.

more likely to have experienced depression than their counterparts whose disease (diabetes) duration was $<5$ years. This finding is in agreement with other similar studies. ${ }^{25,34}$ The increase in the duration of diabetes leads to increased risk of developing diabetes complications. This might increase 
the patient's health care expenditure for health care services. Both diabetes complications and cost might contribute to the development of depression in such patients.

In this study, however, strong predictors of depression like BMI, ${ }^{25,34}$ diabetes complications, ${ }^{11,12,34}$ and regular physical exercise ${ }^{25}$ were not found to be statistically significant to predict depression. This could be due to cultural bias or attributed to the differences in the assessment tool, operational definitions, and study populations (both type I and type II DM patients were included in the current study). In addition, differences in lifestyle, social integrity, perceived severity of the disease, setting, and religion of the patients might strongly contribute for the inconsistency. ${ }^{24,25,34}$

This study has some important limitations that should be kept in mind when interpreting the results. First, the crosssectional nature of the study design does not confirm definitive cause and effect relationship. Furthermore, the study may be prone to reporting bias since the data were collected based on self-reported information. In addition, since the data were gathered from a single hospital, they may not be generalized to all diabetes patients in Ethiopia. Finally, reports for some of the questions were past history or encounters, which are prone to recall bias.

\section{Conclusion}

The prevalence of depression was low as compared to other similar studies elsewhere. There were no reported cases of severe depression. Disease (diabetes) duration and religion were the factors significantly associated with depression. Clinicians need to screen and treat diabetic patients for depression as routine component of diabetes care. Further research with a larger sample size, wider geographical coverage, and segregation of type of DM is recommended.

\section{Acknowledgments}

Firstly, we would like to forward our deepest gratitude to the University of Gondar for ethical approval and financial support. We would like also to thank Mr Abere and Mr Yesuf Endris for their support in the process. Our gratitude and appreciation go to data collectors and study participants. We are also very grateful to UoGH Diabetic Clinic, and the staff working there for facilitating the research work to happen.

\section{Author contributions}

AMB conceived the original idea, was involved in the proposal writing, designed the study, and participated in all the implementation stages of the project. AMB also analyzed the data and wrote the manuscript. BAD participated in the conception of the original idea, was involved in the proposal writing, finalized the write-up of the manuscript, and critically revised the manuscript for important intellectual content. FMA and TDA were responsible for critically revising the research proposal and the manuscript, and participated in its design and interpretation. SAB was involved in the design of the work and approved the version to be published. All the authors read and approved the final version of the manuscript.

\section{Disclosure}

The authors report no conflicts of interest in this work.

\section{References}

1. Wild S, Roglic G, Green A, Sicree R, King H. Global prevalence of diabetes: estimates for the year 2000 and projections for 2030. Diabetes Care. 2004;27(5):1047-1053.

2. Whiting DR, Guariguata L, Weil C, Shaw J. IDF diabetes atlas: global estimates of the prevalence of diabetes for 2011 and 2030. Diabetes Res Clin Pract. 2011;94:311-321.

3. Motala AA, Mbanya JC, Ramaiya KL. Metabolic syndrome in subSaharan Africa. Ethn Dis. 2009;19:8-10.

4. Federal Ministry of Health. National Mental Health Strategy of Ethiopia (2012/13 -2015/16), Addis Ababa. 2012.

5. Bitew T. Prevalence and risk factors of depression in Ethiopia: a review. Ethiop J Health Sci. 2014;24(2):161-169.

6. Hailemariam S, Tessema F, Asefa M, Tadesse H, Tenkolu G. The prevalence of depression and associated factors in Ethiopia: findings from the National Health Survey. Int J Ment Health Syst. 2012;6(1):23.

7. Mezuk B, Eaton WW, Albrecht S, Golden SH. Depression and type 2 diabetes over the lifespan: a meta-analysis 31(12):2383-90. Diabetes Care. 2008;31(12):2383-2390.

8. Knol MJ, Twisk JW, Beekman AT, Heine RJ, Snoek FJ, Pouwer F. Depression as a risk factor for the onset of type 2 diabetes mellitus. A meta-analysis. Diabetologia. 2006;49(5):837-845.

9. Golden SH, Lazo M, Carnethon M, et al. Examining a bidirectional association between depressive symptoms and diabetes. JAMA. 2008;299(23):2751-2759.

10. Katon WJ. Epidemiology and treatment of depression in patients with chronic medical illness. Dialogues Clin Neurosci. 2011; 13(1):7-23.

11. de Groot M, Anderson R, Freedland KE, Clouse RE, Lustman PJ. Association of depression and diabetes complications: a meta-analysis. Psychosom Med. 2001;63(4):619-630.

12. Lin EH, Rutter CM, Katon W, et al. Depression and advanced complications of diabetes: a prospective cohort study. Diabetes Care. 2010;33(2):264-269.

13. Lin EH, Katon W, Von Korff M, et al. Relationship of depression and diabetes self-care, medication adherence, and preventive care. Diabetes Care. 2004;27(9):2154-2160.

14. Gilmer TP, O'Connor PJ, Rush WA, et al. Predictors of health care costs in adults with diabetes. Diabetes Care. 2005;28(1):59-64.

15. Katon W, Russo J, Lin EH, et al. Depression and diabetes: factors associated with major depression at five-year follow-up. Psychosomatics. 2009;50(6):570-579.

16. Bajwa SS, Saroha R, Bajwa SK. Psychosocial concerns among patients with diabetes attending the preanesthetic and pain clinic. J Soc Health Diabetes. 2015;3:72-78

17. Sambamoorthi U, Olfson M, Wei W, Crystal S. Diabetes and depression care among medicaid beneficiaries. $J$ Health Care Poor Underserved. 2006;17(1):141-161.

18. Musselman DL, Betan E, Larsen H, Phillips LS. Relationship of depression to diabetes types 1 and 2: epidemiology, biology, and treatment. Biol Psychiatry. 2003;54(3):317-329. 
19. Chen YH, Lin HC. Patterns of psychiatric and physical comorbidities associated with panic disorder in a nationwide population-based study in Taiwan. Acta Psychiatr Scand. 2011;123(1):55-61.

20. Waitzfelder B, Gerzoff RB, Karter AJ, et al. Correlates of depression among people with diabetes: The Translating Research Into Action for Diabetes (TRIAD) study. Prim Care Diabetes. 2010;4(4):215-222.

21. Ell K, Katon W, Cabassa LJ, et al. Depression and diabetes among low-income Hispanics: design elements of a socioculturally adapted collaborative care model randomized controlled trial. Int J Psychiatry Med. 2009;39(2):113-132.

22. Anderson RJ, Freedland KE, Clouse RE, Lustman PJ. The prevalence of comorbid depression in adults with diabetes: a meta-analysis. Diabetes Care. 2001;24(6):1069-1078.

23. Ali S, Stone MA, Peters JL, Davies MJ, Khunti K. The prevalence of co-morbid depression in adults with type 2 diabetes: a systematic review and meta-analysis. Diabet Med. 2006;23(11):1165-1173.

24. Ganasegeran K, Renganathan P, Manaf RA, Al-Dubai SA. Factors associated with anxiety and depression among type 2 diabetes outpatients in Malaysia: a descriptive cross sectional single-centre study. BMJ Open. 2014;4(4).

25. Khuwaja AK, Lalani S, Dhanani R, Azam IS, Rafique G, White F. Anxiety and depression among outpatients with type 2 diabetes: a multicentre study of prevalence and associated factors. Diabetol Metab Syndr. 2010;2(72).

26. Sweileh WM, Abu-Hadeed HM, Al-Jabi SW, Zyoud SH. Prevalence of depression among people with type 2 diabetes mellitus: a cross sectional study in Palestine. BMC Public Health. 2014;14:163.
27. Igwe MN, Uwakwe R, Ahanotu CA, Onyeama GM, Bakare MO, Ndukuba AC. Factors associated with depression and suicide among patients with diabetes mellitus and essential hypertension in a Nigerian teaching hospital. Afr Health Sci. 2013;13(1):68-77.

28. Erkie M, Feleke Y, Desalegne F, Anbessie J, Shibre T. Magnitude, clinical and socio demographic correlate of depression in diabetic patients, Addis Ababa, Ethiopia. Ethiop Med J. 2013;51(4):249-259.

29. Dejenie Habtewold T, Radie YT, Sharew NT. Prevalence of depression among type 2 diabetic outpatients in Black Lion General Specialized Hospital, Addis Ababa, Ethiopia. Depress Res Treat. 2015;2015:184902.

30. Acee AM, Fahs MC. Can treating depression improve diabetic management? Nurse Pract. 2012;37(1):46-52.

31. GCMHS. Gondar College of Medicine and Health Sciences and Gondar University Hospital Five Year Strategic Plan 2010/11-2014/15. Addis Ababa. 2011.

32. Gelaye B, Williams MA, Lemma S, et al. Validity of the Patient Health Questionnaire-9 for depression screening and diagnosis in East Africa. Psychiatry Res. 2013;210(2):10.

33. Niraula K, Kohrt BA, Flora MS, et al. Prevalence of depression and associated risk factors among persons with type- 2 diabetes mellitus without a prior psychiatric history: a cross-sectional study in clinical settings in urban Nepal. BMC Psychiatry. 2013;13:309.

34. Katon W, Von Korff M, Ciechanowski P, et al. Behavioral and clinical factors associated with depression among individuals with diabetes. Diabetes Care. 2004;27(4):914-920.

\section{Publish your work in this journal}

Diabetes, Metabolic Syndrome and Obesity: Targets and Therapy is an international, peer-reviewed open-access journal committed to the rapid publication of the latest laboratory and clinical findings in the fields of diabetes, metabolic syndrome and obesity research. Original research, review, case reports, hypothesis formation, expert opinion and commentaries are all considered for publication. The manuscript management system is completely online and includes a very quick and fair peer-review system, which is all easy to use. Visit http://www.dovepress.com/testimonials.php to read real quotes from published authors. 